\title{
Guyonne LEDUC (éd.), Réalités et représentations des
}

\section{Amazones}

Paris, l'Harmattan, coll. « Des idées et des femmes », 2008, 486 pages, 26

illustrations

\section{Sophie Cassagnes-Brouquet}

\section{(2) OpenEdition}

1 Journals

\section{Édition électronique}

URL : http://journals.openedition.org/clio/9516

DOI : $10.4000 /$ clio.9516

ISSN : 1777-5299

Éditeur

Belin

Édition imprimée

Date de publication : 15 décembre 2009

Pagination : 280-281

ISSN : $1252-7017$

\section{Référence électronique}

Sophie Cassagnes-Brouquet, « Guyonne Leduc (éd.), Réalités et représentations des Amazones », Clio. Histoire, femmes et sociétés [En ligne], 30 | 2009, mis en ligne le 01 février 2010, consulté le 21 septembre 2020. URL : http://journals.openedition.org/clio/9516; DOI : https://doi.org/10.4000/clio. 9516

Ce document a été généré automatiquement le 21 septembre 2020.

Tous droits réservés 


\section{Guyonne LEDUC (éd.), Réalités et représentations des Amazones}

Paris, l'Harmattan, coll. « Des idées et des femmes », 2008, 486 pages, 26 illustrations

\section{Sophie Cassagnes-Brouquet}

\section{RÉFÉRENCE}

Guyonne LEDUC (éd.), Réalités et représentations des Amazones. Paris, l'Harmattan, coll. « Des idées et des femmes », 2008, 486 pages, 26 illustrations.

Point d'orgue de foisonnantes journées d'études organisées par Guyonne Leduc à l'Université de Lille III, cet important volume qui regroupe une trentaine de contributions propose une vision kaléidoscopique et pluridisciplinaire d'un mythe à la fois historique et littéraire, celui des Amazones, présent dans notre imaginaire depuis plus de deux mille ans. Tourné vers l'histoire, le livre veut aussi rendre compte des dernières évolutions de ce mythe.

2 Figures imaginaires, mythologiques, ou littéraires, mais aussi femmes réelles, sont ainsi convoquées depuis l'Antiquité jusqu'à la période la plus contemporaine. Les textes, mais aussi l'iconographie, soutiennent cette approche. L'ouvrage s'organise en cinq parties : la première est précisément consacrée à l'imagerie des Amazones, depuis les vases grecs jusqu'au cinéma muet en passant par la peinture baroque. La deuxième s'interroge sur le rapport entre ces femmes guerrières et le pouvoir. Elle est suivie d'une troisième et quatrième partie dédiées aux figures littéraires. L'une est consacrée au théâtre, depuis la scène élisabéthaine jusqu'à la célèbre Penthésilée d'Heinrich Kleist, en passant par le siècle d'Or espagnol avec Tirso da Molina et la littérature romantique avec la Pucelle d'Orléans de Schiller; l'autre partie s'attache aux évolutions du mythe dans la littérature, depuis le roman médiéval jusqu'aux auteurs des $\mathrm{XIX}^{\mathrm{e}}$ et $\mathrm{xx}^{\mathrm{e}}$ siècles, au travers des exemples de Kleist, de Gracq, de Wolf et de Jelinek. Enfin l'ouvrage se termine sur quelques figures de femmes réelles, Amazones et femmes de 
pouvoir. C'est donc un très vaste et ambitieux programme soutenu par la richesse des contributions des auteurs et leur diversité.

Les Amazones grecques sont bien sûr présentes, mais elles trouvent un écho dans les femmes guerrières, recherchées et parfois trouvées par les Européens en Amérique au $\mathrm{XVI}^{\mathrm{e}}$ siècle et plus tard dans l'Afrique coloniale. Elles sont liées à l'imaginaire grec des marges, barbares et orientales ; c'est pourquoi, dans l'Europe de la Renaissance nourrie des auteurs antiques, le mythe s'exporte si facilement en Amérique. Christophe Colomb, le premier, situe l'Ile des Amazones en Martinique, à proximité de celle des cannibales, les Caribéens. L'Amazone fait partie de l'imaginaire du colonisateur mais, au XIXe siècle, l'anglais Richard Francis Burton qui décrit en 1863 celles que l'on appelle les Amazones du Dahomey tente de détacher la réalité du mythe.

4 Pour les Grecs, le mythe des Amazones est d'abord un mythe d'inversion ; l'exclusion des femmes est un rêve, leur sécession un cauchemar. L'Iliade mentionne ces femmes égales aux hommes au combat. Leur nom dérive peut-être du grec a-mazos, sans sein, car elles sont réputées pour se couper le sein afin de mieux tirer à l'arc. Les auteurs grecs les placent en des lieux variés depuis Ephèse et Smyrne jusqu'à la Lybie, ou encore en Scythie. Ils insistent tous sur leur force, leur fierté, leur indépendance, mais aussi sur leur sexualité.

5 Si l'incrédulité face au mythe apparaît à l'époque moderne avec Voltaire, la croyance en un pays des Amazones en Amérique est prégnante au XvI ${ }^{\mathrm{e}}$ siècle, de Colomb à Ralegh. Une puissante mythologie des Amazones est établie en Amérique avant même que la rivière Maranon soit nommée ainsi. L'histoire du nom de la rivière commence avec Francisco Pizarro quand il envoie son frère Gonzalo à la recherche de El Dorado. Le capitaine Francisco de Orellana atteint la rivière en décembre 1541, il entend parler d'Amazones et d'or et combat contre quelques femmes. Quand il revient en Espagne, il raconte son aventure et la rivière prend rapidement le nom d'Amazone.

6 Le mythe a fait aussi l'objet de nombreuses appropriations dans une perspective philogyne et féministe; reines et régentes $d u x I^{e}$ siècle s'en emparent au prix d'un adoucissement de la figure guerrière. Au XVII ${ }^{e}$ siècle, Madame de Saint-Balmont prend l'image d'une Amazone chrétienne de la Contre-Réforme, la frondeuse Madame de la Guette qui adopte aussi cette posture, tout comme Catherine II de Russie et le chevalier d'Eon un siècle plus tard. Au début du $\mathrm{xx}^{\mathrm{e}}$ siècle, des féministes lesbiennes comme Natalie Barney revendiquent l'indépendance et l'altérité de l'Amazone et assument l'exclusion des hommes. La figure de l'Amazone occupe toujours une place importante dans le féminisme des années 1970 car elle représente la subversion de l'ordre des sexes. De nos jours, elle est regardée avec plus de distance, peut-être en raison de sa violence. 